\title{
The psychological impact of food allergy and undergoing a food challenge test in adult age
}

\section{INTRODUCTION}

Food allergies are an abnormal response of the body to otherwise harmless food proteins invo ing the immune system (1). The prevalence of food allergy has increased in recent decades and is nวw recognised as a substantial public health burden in developed countries with up to $10 \%$ affected $(2,3 !$ Sy. - ptoms vary and can involve the skin, oropharyngeal tract, gastrointestinal tract, respiratory and carc ic va ,cular systems, with the most severe and sometimes fatal manifestation being anaphylactic shock. Fr od $z^{\prime}$ lergy has an unpredictable nature and individuals with only mild reactions may have a severe ar.' ' lı chreatening reaction on re-exposure.

Although research into possible treatments for food allergy including imm 'inc "L.erapy is being carried out, there is currently no cure. Food allergic individuals must carefully avoici he r ausal foods on a daily basis and carry emergency treatment such as adrenaline in case they have a reaci, $n$. Thus, living with food allergies constitutes a unique stressor that is both chronic and acute, , ?. facing a daily threat of accidental allergen ingestion compounded by acute stress during allergir re ctio is (4).

Diagnosis of food allergy involves taking a detailed clinical histc , y to guide the requirement for skin prick and/or serum specific immunoglobulin $\mathrm{E}$ (slgE) testing. ' $\mathrm{N}$ ', en the clinical history and tests alone cannot provide a definitive diagnosis, or when the possibili. or - ving outgrown an allergy exists, an oral food challenge is essential (5). A food challenge involve',.$\cdot{ }_{5}$, aded administration of the potential culprit food in order to identify if an individual is allergic or ton "ar $i$, thereby confirming or excluding a diagnosis of food allergy.

There is evidence that food allergy can $\mathrm{I}$. $\mathrm{ad}+\mathrm{J}$ increased anxiety about food safety, social isolation and exclusion, and emotional pressure $\mathrm{r}_{\mathrm{f}} \mathrm{a}^{+} \mathrm{c}^{\mathrm{\gamma}}$ to constant vigilance; impacting well-being, mental health and quality of life (6-8). While some quant - - ive studies have examined the effect of food challenge tests on HRQoL (9-14), the majority have $\mathrm{w}$ 'en on children/adolescents or their carers. To our knowledge, only one study has included adults and was tone in the context of a double-blind, placebo-controlled food challenge (DBPCFC) (14). It found that 'IRL 'L scores improved significantly after a DBPCFC when all outcomes of the test were combined coms, red to a control group with greater improvements after a negative outcome when a food allergy wa ; rul a out than a positive outcome (food allergy confirmed). However, there is a need to assess whet', $\mathrm{ur}_{\mathrm{t}}$, is is the case for open food challenges which are the type of food challenges more commonly por iurr ,ed in clinical practice rather than DBPCFC.

Another asne $\mathrm{c}_{2}$ that has received little attention in the context of food allergies is the role of health anxiety. People wi o ar : anxious about their health are more likely to misinterpret health information as personally threatt $\eta_{1} \cdot \sigma(15,16)$; show adverse emotional reactions to ambiguous diagnostic test results, and are less rea ' 'u. ' ' following the medical investigation of symptoms, even when there is no evidence of disease (e.g. 17,18 ). 3ased on these findings, people with high health anxiety may be less reassured by a negative allergy test than people low on health anxiety. 
The present study was designed to assess the psychological impact of food allergy and open food challenges on HRQoL, emotional distress, health anxiety and negative mood in an adult population. Based on previous research we predicted that: 1 ) there would be better HRQoL and lower emotional distress, health anxiety and negative mood in people who test negative following a food challenge test. 2) ' $R Q_{\mathcal{L}}$ '. would improve among all people undergoing a food challenge test, but to a greater extent amo' ${ }^{\prime}$ ' רe ple

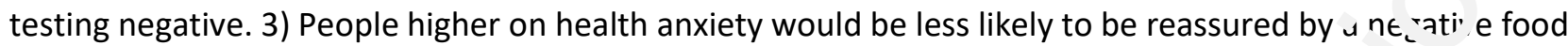
challenge.

\section{MATERIALS \& METHODS}

Design

This research consisted of two studies: 1 ) a cross-sectional study that com ${ }_{1}$, red HRQoL and psychological measures among adults with clinician confirmed food allergy diagnc is (based on clinical history, skin prick and/or serum slgE testing) vs. adults who had undergone a food ' la' '?nge test and 2) a prospective study that examined changes among people undergoing a food char '- ns 't'st.

A negative challenge was defined as tolerating the food ' $\cdots i_{1}$ - - $\lrcorner$ t any evidence of allergic symptoms, thus allergy to the food tested was excluded while a positiv ' ut come required the presence of symptoms and objective signs consistent with IgE mediated food alie.

Ethical considerations

The North East-Sunderland National Researrh ${ }_{2}{ }_{h} h_{\text {_ }}$ s Service (NRES) Committee approved this research project in September 2013 (REC reference: 13/ $\mathrm{N}$ E/0271). Following this, Research and Development approval was sought from the Royal Brc npt $\wedge n$ and Harefield NHS Foundation Trust and was granted (2013AT007B). The research was con'.te $v$ in accordance with the ethical standards established in the Declaration of Helsinki and informea $\mathrm{c}$, $n$, ent was obtained from all participants before enrolment in the studies.

Recruitment and participants

Study 1

Individuals that had pre viou ily attended the Allergy Department at Royal Brompton \& Harefield NHS Foundation Trust, Lr $\mathrm{nN}^{-}-\eta$ and were diagnosed with food allergy based on clinical history, skin prick and/or slgE tests (Group : FA- $:$ :o challenge ) or who had previously undergone a clinically indicated food challenge (Group 2-Food C: alle ige) were identified from the medical records. The inclusion criteria for participating in this study wer aged 18 or older, clinician confirmed IgE mediated food allergy or previous food challenge. Indı. Tuals could not participate if they were considered adults with incapacity.

Study

All I. TIvin dals who were waiting to have a food challenge test between October 2013 to March 2015 were invited to participate in the study. Fifty-six individuals were eligible to participate. 


\section{Demographic characteristics}

Participants were asked to record their age, gender, ethnicity and educational qualifications.

Food allergy characteristics

Specifically designed questions were used to assess the foods that previously caused allergic sy nptı ms, age when first experienced a reaction, treatment received, investigations for food allergy $\neg$ ra . Jrenaline auto-injector possession. Participants who had undergone a food challenge test were ask ${ }^{-1} a_{n}$ - ut the number and type of food/s they had tested, time between the initial reaction and the $\mathrm{fc} x \mathrm{cliallenge}$ test to the suspect food and outcome of the challenge.

Health-related quality of life

The FAQLQ-Adult Form was used in this study as this is the only disease-specit, HRI LoL questionnaire for food allergic adults (19), using a 5-point Likert scale with response options: $0-n_{2}+$ at all, 1-slightly, 2moderately, 3-very and 4-extremely. It has four subscales which can be $\mathrm{r}^{n m_{\mathrm{L}}}$ "- ed to generate a total HRQoL score: Allergen Avoidance and Dietary Restrictions (AADR), exarı., le i em 'How troublesome do you find it that you have to be alert to what you are eating?'; Emotional I npact (-!), example item 'How frightened are you of accidentally eating the wrong food?'; Risk of Ac idental Exposure (RAE), example item 'How troublesome is it that labels are incomplete?'; Foo'? A ery elated Health (FAH), example item 'How worried are you that it is unclear to which foods you are a.' ${ }^{\circ}$ rgıc?'. In Study 1, participants who had undergone a food allergy challenge test were asked to corn. lete this in relation to their perceived quality of life now and prior to completing the challenge test. In Stu ' $v 2$, articipants completed the questionnaire before the food challenge and three months after.

\section{Emotional distress}

Emotional distress was measured using the 12-ite.' vf ision of the General Health Questionnaire (GHQ-12) (20). Responses were scored 0-3 and were su $\mathrm{nr} \in \mathbb{t}$ t tu produce a scale from 0 to 36 , with higher scores indicating greater distress.

\section{State anxiety}

State anxiety was assessed with the 'a' ' ' ' 'ted 6-item version of the Spielberger State Trait Anxiety Inventory (STAI) with response option: - $n$ a 6 point scale (21). Responses were totalled giving a score of between 6 and 24, with higher su res indicating higher anxiety.

Positive and Negative Aff $\epsilon$ zt $w$ ` $r$.easured using the Positive and Negative Affect Schedule (PANAS) (22). Participants were asked $h r . w L_{1}$. эy ieel 'right now'. Participants were asked to rate the extent to which they experienced each of the cmu ': 'ons on a 5-point Likert scale ranging from "very slightly or not at all" to "extremely". Both subs ᄀler range from 10 (low) to 50 (high).

Health anxiety

A shortened varsic. - ff the Health Anxiety Questionnaire (HAQ) $(23,17)$ was used in this study in order to assess the pi , sence of health anxiety in our study population. Participants responded using a 4-point Likert scale 'not at ." or rarely', 'sometimes', 'often', 'most of the time', with responses averaged to give scores from . . 14, " th higher scores indicating higher levels of health anxiety.

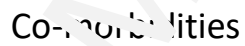

Participants were asked whether they suffered from any other allergic conditions or any other medical conditions. 
Reassurance following a negative test was assessed with the following items: 'If your test to any food was NEGATIVE (i.e. no symptoms) how reassured are you that you are not allergic to that food?'. Response options were: 'Not at all', 'Slightly', 'Moderately', 'Very' and 'Extremely'.

Food re-introduction. Participants were also asked if they had re-introduced the food back into the.: diet if their food challenge test was negative (response options: 'Yes, small amounts', 'Yes, normal an oun s', 'No, still avoiding' or 'No, haven't re-introduced but not avoiding'). If they had not re-introduced IL, 'Nriat were the reasons (response options: 'Fear of reaction', 'Not convinced of negative test', 'Reactinn ८ ? zating food after challenge', 'Not confident to try alone', 'Other').

If your challenge was negative, does this mean that you no longer need to carry a. ᄀy $\epsilon$ ner ,ency medication? 'Yes' 'No, I have other allergies'

Procedure

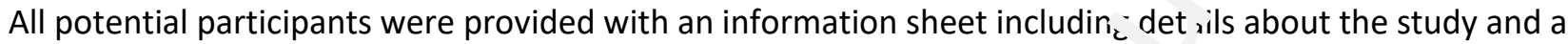
copy of the questionnaire. They were informed that participation was vc ur. . $r y$ and that they had the right to withdraw at any time during the study. Furthermore, declining to take $r^{-} \cdot \mathrm{c}$ in the study would have no impact on their care. They were also provided with the researchers - ontact details in case they had any questions about the research. If they wished to take part, they ha is give written informed consent and complete the questionnaire provided with the information sh, $r . t$. nd return in the enclosed stamped selfaddressed envelope.

\section{Data analyses}

Statistical analyses were performed using SPSS softwal ? 、IB $\wedge$ SPSS Statistics for Windows, Version 23.0, Armonk, NY: IBM Corp). Differences between groups ، 'are assessed using either General linear model (GLM) for continuous data or chi-square/ Fisher's exac' test for categorical data. Linear regression was used to assess differences between the groups on $m=: s u_{1}$ 's of HRQoL, emotional distress, health anxiety and mood. GLM was used to assess change in HRQ' $b$ ' tween the two food challenge groups. The percentage of missing data was less than $5 \%$.

The sample size was calculated to detec a $m$ edium effect size (Cohen's $\mathrm{f} 2=0.15$ / Cohen's $\mathrm{f}=0.25$ ) at $80 \%$ power and $5 \%$ significance level. For . $n$ '. 'inear regression, assuming ten predictors, the sample size was 118. For GLM to detect changes in pre $=.1$ d post-challenge HRQoL scores for 2 groups (food challenge positive or negative) across two .. ne points (before and three months after the test), the total sample size was 34 (G*Power, version $3.1 /$ ) (:4).

\section{RESULTS}

\section{Study 1}

In total 276 indi: 'Nua s participated. Group 1 (FA-No challenge) consisted of adults with clinician confirmed food allergy $k \lambda$. ho had not undergone a food challenge test. The response rate for Group 1 was 83.2\% with 208 aNilt. ' $69.7 \%$ female- $n=145$ ) consenting to participate out of 250 eligible individuals. Group 2 (Food $\mathrm{Ch}_{c} !$ !r. $n \xi$ ) included 68 adults who had previously undergone a food challenge test. All challenge tests $u \%$ c cınically indicated either for diagnostic purposes i.e. inconclusive skin prick/slgE tests or to ass ' ' - dividuals had outgrown an allergy i.e. suspected to no longer be allergic. The response rate for this gru.ip was 59.1\% (68 out of eligible 115 individuals participated). Fifty percent of the 68 participants $(n=34)$ had a negative challenge outcome i.e. allergy to tested food excluded (FC-Negative) and $50 \%(n=34)$ had a positive challenge test to a food (FC-Positive) i.e. allergy confirmed. 
In the total study sample $(n=267)$, the majority were female $(69.2 \% n=191)$, had educational qualifications (97.8\%, $n=261)$, and identified their ethnicity as White $(73.6 \%, n=203)$. There were significant differences between the groups in age $(F(2,273)=4.138 ; p=0.017)$; post-hoc comparisons showed the FC-Positive group were significantly older than Group $1(p=0.024)$, but there was no difference in age between the $F^{\prime}:-P_{0}$. tive and FC-Negative subgroups ( $p=1.000)$. There were no significant differences between the grour, $\therefore$ t t $; \mathrm{ms}^{-}$ of gender, ethnic group, or educational level (Table I).

As is common in individuals with food allergies, many of the participants suffered with other " "r.rgic conditions. These included: asthma 59.1\% ( $n=163)$ and allergic rhinitis $68.8 \%(n=190)$, al $h, u_{i}, i$ prevalence of other comorbidities such as heart disease was low. The FC-Positive group were mc e likeıy to have asthma than Group 1 (OR: 3.559, 95\% Cls: 1.414 to 8.962, p<0.007), and the FC-Nes 'tı = sroup (OR: 4.667, 95\% Cls 1.540 to $14.143, p=0.006$ ) with no difference between the FC-Negative grou. ? and Group 1 (OR: $1.311,95 \% \mathrm{Cls}: 0.634$ to $2.710, \mathrm{p}=0.465$ ). There were no differences between ${ }^{-1}$ e gi sups on other allergies or comorbidities.

Food allergy profile, diagnosis and treatment

Food allergy profiles across the groups are shown in detail in Tabl $\therefore$ i. Furty-nine percent $(n=112)$ reported that they had previously experienced symptoms consistent $w{ }^{\text {th }}$, a ?ar , lylaxis.

There were no significant differences between the groups .- terms of age of allergy onset, food type, anaphylaxis and treatment received. There was a significa 't dl ierence in gastrointestinal (GI) symptoms between groups, with the FC-Negative less likely to ref ו II symptoms than Group 1 ( $p=0.017)$, but no

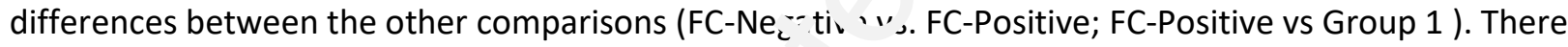
were no significant differences between the grour: $n$ …e other symptoms.

Among participants who underwent a food che".: ng - the mean length of time between first experiencing symptoms to the suspect food and undergoins : fo sd challenge to that food was 12.47 years, ranging from one month to 50 years.

\section{Adrenaline auto-injector possession}

$65.2 \%(n=180)$ of all participants , norted that they were advised to and were carrying adrenaline autoinjector devices. There was a ign, 'icant reduction in the proportion of people who reported carrying an adrenaline autoinjector whc ${ }^{+}$es. $\cdot d$ negative in the food challenge, $(85.3 \%, n=29$ pre-challenge vs. $61.8 \%$, $n=21$ post-challenge; $p=0.2$ ?1). In the FC-Positive group there was no significant change $(52.9 \%, n=18$ prechallenge vs. $67.6 \%, n=! 3 p$ ist-challenge; $p=0.227$ ).

Health-related c 'alit of life

The FC-Nega、 ve gı oup reported better HRQoL than Group 1, even after adjusting for age, presence of asthma ar d '-' symptoms (factors that had differed across the three allergy groups). There was no differ...-e i. ' Jtal HRQoL scores between the two groups with confirmed food allergy (FC-Positive vs Group 1) in boi' $u_{1}$ Iadjusted and adjusted analyses (Table III). Presence of both asthma and GI symptoms were pred ${ }^{+}$ive of poorer HRQoL ( $p=0.006$ and $p<0.001$ respectively). The same pattern of significant results was seen in the HRQoL sub-scales AADR and FAH. No differences were observed between the FC-Positive or FCNegative groups in comparison with Group 1 once the Bonferroni correction had been applied. 
Emotional distress and mood

There were no differences between the three groups on emotional distress, state anxiety, or positive and negative affect. The FC-Positive group reported lower levels of health anxiety than Group 1 in botr unadjusted and adjusted analyses, although this was no longer significant following a Bonferroni cu.rection (Table III).

\section{Change in $\mathrm{HRQ}$ oL in food challenge group}

The GLM analysis showed a significant effect of time, with improvements in HRQCL (F ' $1, F j)=44.40$, $p<0.001)$. There was a non-significant trend between outcome of challenge and $c_{1}$. $n^{\prime}$ : in HRQoL, $F(1,66)=$ 3.077, $p=0.084$, with a higher improvement in HRQoL scores in the challenge $n$ gat: re than the challenge positive group ( 0.762 vs 0.445 respectively).

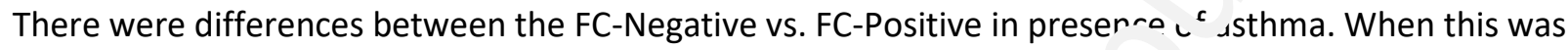
entered into the model, improvement in HRQoL over time remained sig. ifica it $(p<0.001)$ and the interaction became non-significant $(p=0.214)$.

\section{Reassurance in results}

The mean levels of reassurance following a negative outcc $n \in$ vere 3.882 (SD=1.274), with $47.1 \%$ ( $n=16)$ responding 'extremely', 17.6\% (n=6) 'very', 14.7\% (n=5) 'mu '.-rately', 17.6\% ( $n=6)$ slightly and 2.9\% 'not at all' reassured. The correlation between health anxietv $r$. $\mathrm{r}$ zassurance for people testing negative was $0.076, p=0.670$.

\section{Food re-introduction}

Participants with a negative challenge ol'..0.... responded that $76.5 \%$ had re-introduced the food tested back into their diet in normal amounts 0 . sm $\mathrm{yll}$ amounts. $2.9 \%$ had not re-introduced but were not specifically avoiding while $20.6 \%$ we e ' $\iota^{\prime \prime}$ avoiding. The reasons given by those still avoiding were: fear of reaction $(n=2)$, not confident to try alo. . $(n=4)$ and reaction on eating food after challenge $(n=1)$.

\section{Study 2}

Fifty-three out of 56 eli , Ible ı,dividuals, agreed to take part (response rate $94.6 \%$ ), completing questionnaires befor $t_{1},-$ sod challenge test (while on the waiting list) and immediately after test completion. 45 test $\therefore$ nf gative, and only 8 tested positive. Forty participants (75.5\% response rate) completed a questio, naire three months after the challenge. Thirteen participants did not complete the final question - -ire nespite being sent a reminder. The mean age of the 53 participants was 33.5 years $(S D=12.5)$ wic. a range of 18 to 62 years. $71.7 \%$ were female, $84.9 \%(n=45)$ had educational qualifications and the $\mathrm{r} \mathrm{aj}^{\prime},{ }^{+}+\mathrm{y}$ identified their ethnicity as White $(69.8 \%, \mathrm{n}=37)$. Many of the participants suffered with other $\therefore$ rg. - onditions in particular, asthma $62.3 \%(n=33)$, allergic rhinitis $60.4 \%(n=32)$ and atopic de matiı $49.1 \%(n=26)$.

The samiple included participants with a range of food allergies and symptoms. The mean number of foods that participants reported as having previously experienced symptoms to was 3.09 (SD=2.41, range 1 to 11 foods). $47.2 \%$ had experienced symptoms to peanut, $43.4 \%$ to tree nuts, fruits $37.7 \%$, shellfish $34 \%$, fish $24.5 \%$ as well as a variety of other foods. The symptoms experienced included oropharyngeal $64.2 \%$, skin 
$71.7 \%$, upper airway $30.2 \%$, respiratory (lower airway) $43.4 \%$, gastrointestinal $50.9 \%$ and anaphylaxis $37.7 \%$. The mean age when individuals first experienced allergic symptoms to any food was 20.5 years (SD=16.4, rang 6 months to 56 years).

The most common foods that were tested with food challenge were tree nuts $(34 \%, n=18)$, shellfis. $(24.5 \%, n=13)$, peanut $(20.8 \%, n=11)$, and fish $(17 \%, n=9)$. The average time between first expe rien ing symptoms to a food and undergoing a challenge test to the suspect food was 8.58 years $(S D=:$ 10) (range 3 months to 32 years; median 3 years).

Health-related quality of life

Change in HRQoL over time was computed for responders to the follow-up ques+io, na $a_{1}$, , and using an intention-to-treat analysis, where baseline scores of non-responders were used $\lambda \varsigma$ ॥ low-up scores, thereby assuming no change in HRQoL (Table IV).

In the 40 participants who completed the questionnaires at all time points, 'her : was a significant change from before and after the challenge test in mean total score $F(1,39)=16$. $80 i \quad p<0.001$. Intention to treat analysis was also significant $(F(1,52)=15.346 ; p<0.001)$.

Significant differences were observed across all four subscales of the , 'RQoL questionnaire, although applying a Bonferroni correction (adopting a revised p value $s$. $0.0 \mathrm{j}$ ) meant the change in RAE was no longer significant (Table V).

The results showed significant improvement in HRQoL foll, w. ' 9 a food challenge in those testing negative. The small sample size among people testing positive mean $n^{\text {th }} \leq$ study was underpowered to test for differences in HRQoL according to test outcome.

Emotional distress and mood

There were no significant changes in emotiona'. " "str $-\varsigma$, health anxiety, state anxiety or positive mood over time (Table VI). There were significant differe, es Jver time in both the PANAS-negative score and state anxiety, due to lower anxiety and negative noo $\mathrm{I}$ after the test than at baseline, but no differences between baseline and three months por $i$-ch רוlenge (Table VI).

Adrenaline auto-injector posses " on

Prior to the challenge, $60.4 \%$ ( $n=3$.') of participants in the whole sample $(n=53)$ reported that they possessed adrenaline auto-i $i_{1}: c_{2}, r$ devices. Following the challenge only $50.9 \%(n=27)$ still required these. In the group who tested $n_{c}$; tive $(n=45)$, the change in proportion of people carrying adrenaline autoinjectors approach ad si snificance $(60 \%, n=27$ vs $49 \%, n=22, p=0.063)$. There was no difference in the challenge positive gr uun but the sample size was very small.

Reassurance in $r_{c}{ }^{-1}$ llts

The mear Ie' $/$ 's of reassurance following a negative outcome were 4.000 (SD=1.247), with $46.4 \%$ ( $n=13$ ) respo, ing '- Atremely', $25.0 \%(n=7)$ 'very', 17.9\% ( $n=5)$ 'moderately', 7.1\% ( $n=2)$ slightly and $3.6 \%(n=1)$ ' $n r$ ' st a." reassured. The correlation between health anxiety and reassurance for people testing negative

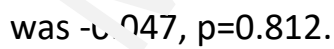


Three months after the challenge, $95 \%$ of participants had introduced the food tested into their diet (50\% normal amounts, $45 \%$ small amounts). The reasons given by the $5 \%$ still avoiding the food were: fear of reaction, not confident to try alone, reaction on eating food after challenge and not convinced of the negative test.

\section{DISCUSSION}

We examined HRQoL, emotional distress, health anxiety and mood among adults under o ng a food challenge, using both cross-sectional and prospective study designs. Study 1 showed hat raults who had tested negative (FC-Negative) reported better HRQoL than people living with a c'ini : $7 r_{1}$ vilagnosed food allergy who had not undergone a food challenge (Group 1). There were no differonc $\backsim$ in HRQoL between the FC-Positive group and Group 1. These results remained significant controli. $\mathrm{g}$ fo age, and presence of asthma or Gl symptoms, which varied between the groups. The groups did no vitier in relation to emotional distress, health anxiety or positive and negative mood. However. $\therefore$ - o overall sample mean for GHQ-12 was above the scores of 11-12 which is considered to indicate $i$ risk f being diagnosed with a mental illness (20) thus showing that some food allergic adults have high lew Is of psychological distress.

Consistent with previous research (14) there were significant i.., , rovements in HRQoL over time. The retrospective study (Study 1 ) showed significant changes i.. ${ }^{+}$otal HRQoL scores, with improvements in two out of four of the subscales (Allergen Avoidance \& Dietary Resi, ictions and Food allergy related Health), while the prospective study (Study 2) showed significar ، . iprovements in three, with positive changes also observed in Emotional Impact. This suggests people $r a$, $h$ - ve greater difficulty recalling the emotional impact of an allergy than other aspects. Following - nez_ive challenge, fewer individuals reported a need to carry adrenaline auto-injector devices than thc $\_w$ th a positive test. However, it is not clear why the FC-Negative group did not report lower levels sf : $i-k \iota^{c}$. Accidental Exposure when they have had allergies to particular food groups ruled out.

Contrary to predictions we found no $\mathrm{ul}^{\text {; }}$-rences in HRQoL among people testing positive compared with those testing negative. In Study 1 , the $n$ 'eraction between time and food challenge outcome approached significance, but once group dift .. 'snces in the prevalence of asthma were controlled for, the interaction become non-significant. Havir g a_ 'hma was a significant independent predictor of HRQoL which is consistent with previous fin ${ }^{\text {ing. }}:(8)$. Food allergies often co-exist with asthma (25), and can also trigger or worsen asthma symptom. makıng this relationship more complex (26). Study 2 had too few positive challenge outcomes to est ${ }^{\prime}$ or group difference in HRQoL. Previous research has shown people testing positive also report ir.zreures in quality of life, although to a lesser extent than people testing negative (14). The benefits of a posilvr. test include greater certainty about which foods to avoid, allowing the affected individual to develop :daptive strategies to better manage their condition that may lead to improvements in HRQoL.

A novt' a ' neut of this study was that health anxiety was also measured that has not been studied $\mathrm{pr}, \mathrm{n}^{\prime} \cdot \mathrm{c}_{1}$ ' in food allergic individuals. Health anxiety refers to apprehension and fear that changes in bodily sensat , ns may be indicative of a serious illness (16). Individuals with high health anxiety often fail to be reassured by medical tests (e.g. 17). However, among the negative challenge participants, there was no significant association between reassurance and health anxiety, but this part of the study was underpowered. Following a negative challenge, individuals are advised that they can introduce the food 
that they were avoiding back into their diets. In Study 2, 95\% of participants re-introduced the food. However, in Study 1 only $76.5 \%$ had done so. This is an area that requires further studying in order to understand the reasons why individuals may not be convinced or trust the result to eat the food again.

Of concern is the average time participants reported between first experiencing symptoms in a ' $n \cap \mathcal{d}$ and undergoing a challenge test to the suspect food: 12.47 years in Study 1 and 8.58 years Stuc, ?. 1.iis may also reflect the lack of education of the public regarding food allergies in adults as well $a, t$, , - limited adult allergy services in the UK and the provision of food challenge tests. There is now also $F^{\prime}$ id $n$. e that delaying food challenge tests is associated with direct and indirect economic cost: $(2,28$.

\section{Strengths and limitations}

A strength of this study is that it explored an area and a population that hacに - _ived little attention, exploring HRQoL in adults with clinician-diagnosed food allergy and wh had undergone a clinically indicated open food challenge in the UK using a disease specific ques 'ionnaı ?. Furthermore, emotional psychological distress, mood and health anxiety were assessed which ': 'as also not been explored in this group.

The large sample of food allergic adults allowed for inclusi in o participants with different ages and types of food allergies. However, a larger prospective study i' $n^{\prime}$ 'eded to adequately assess whether FC-Positive and FC-Negative groups differ in relation to HRQoL, $-10 \cdots$ dssess the relationship between health anxiety and failure to be reassured following a negative te,.

In the prospective study, participants were collowed at three months after the challenge test. Future studies can potentially assess HRQoL at Iras " weriods of time after challenge to assess whether this benefit from undergoing a challenge tes is $r$ aintained as was the case in the retrospective study. Strategies for achieving a good respr $n \varsigma=$ " - te will need to be considered as in this study we found the response rate for the follow up questic - laire was reduced.

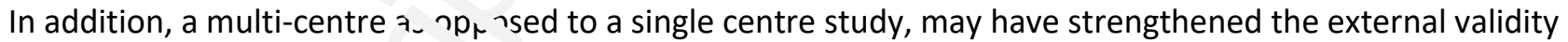
of our findings and reduce $i^{\prime}$ any potential bias due to other aspects of care received by participants that may have positively im, 'acte $d$ on their experience.

\section{CONCLUSIONS}

The findings $1.7 m$ this research indicate that the issues of living with food allergy faced by adults have a negative i $\mathrm{nr}^{-1}$ on their HRQoL. Undergoing an open food challenge test was found to significantly impro $c 4 R$ ? $\mathrm{JL}$. By making these tests more widely available in clinical practice and clarifying whether an in ' ' ', iduc ${ }^{\prime}$ is allergic or not, any uncertainty can be dispelled, unnecessary food restrictions can be avoided and h. 20 L can be improved. 
The authors declare that they have no conflict of interest.

\section{FUNDING}

This research received no specific grant from any funding agency in the public, commercial, or not for-p; ofit sectors.

\section{REFERENCES}

1. Sampson HA, Aceves S, Bock SA, James J, Jones S, Lang D, Nadeau K, Nowak-Wegrz in A, Oppenheimer J, Perry TT, Randolph C, Sicherer SH, Simon RA, Vickery BP, Wood R; Joint Task For 'o c. H I actice Parameters, Bernstein D, Blessing-Moore J, Khan D, Lang D, Nicklas R, Oppenheimer J, Portnn:? I, ? ' 'ndolph C, Schuller D, Spector S, Tilles SA, Wallace D; Practice Parameter Workgroup, Sampson HA, A v ove' S, Bock SA, James J, Jones S, Lang D, Nadeau K, Nowak-Wegrzyn A, Oppenheimer J, Perry TT, Randc.' 'h C, Sicherer SH, Simon RA, Vickery BP, Wood R. Food allergy: a practice parameter update-2014 ' $A_{1}$ '" gy Clin Immunol. 2014;134(5):1016-25.

2. Renz H, Allen KJ, Sicherer SH, Sampson HA, Lack G, Beyer K O€ 'tgeı. HC. Food allergy. Nat Rev Dis Primers. 2018;4:17098.

3. Sicherer SH, Sampson HA. Food allergy: A review anr U'd'ate on epidemiology, pathogenesis, diagnosis, prevention, and management. J Allergy Clin Immunı' 2u_ú; 141(1):41-58.

4. Cummings AJ, Knibb RC, King RM, Lucas JS. $r=k$ sycnosocial impact of food allergy and food hypersensitivity in children, adolescents an 1 their families: a review. Allergy. 2010;65(8):933-945.

5. Muraro A, Werfel T, Hoffmann-So nr.1t gruber K, Roberts G, Beyer K, Bindslev-Jensen C, Cardona V, Dubois A, duToit G, Eigenmann P, Fernaıldez Rivas M, Halken S, Hickstein L, Høst A, Knol E, Lack G, Marchisotto MJ, Niggemann B, NW : rı: BI, Papadopoulos NG, Poulsen LK, Santos AF, Skypala I, Schoepfer A, Van Ree R, Venter C, Worm N" Vlit g-Boerstra B, Panesar S, de Silva D, Soares-Weiser K, Sheikh A, BallmerWeber BK, Nilsson C, de Jo's VVu, Akdis CA; EAACl Food Allergy and Anaphylaxis Guidelines Group. EAACl food allergy and anaphylax.: guidelines: diagnosis and management of food allergy. Allergy. 2014;69(8):1008-25.

6. Ravid NL, Ann u 'zi: to RA, Ambrose MA, Chuang K, Mullarkey C, Sicherer SH, Shemesh E, Cox AL. Mental health and q' alit, of-life concerns related to the burden of food allergy. Psychiatr Clin North Am. 2015;38(1'.?7-0?.

7. 7 t 'te I,$\Lambda$, Biedermann T, Rapps $N$, Hausteiner C, Henningsen P, Enck P, Zipfel S. Psychological burden of food allergy. World J Gastroenterol. 2007;13(25):3456-65.

8. Jansson SA, Heibert-Arnlind M, Middelveld RJ, Bengtsson UJ, Sundqvist AC, Kallström-Bengtsson I, Marklund B, Rentzos G, Åkerström J, Östblom E, Dahlén SE, Ahlstedt S. Health-related quality of life, 
assessed with a disease-specific questionnaire, in Swedish adults suffering from well-diagnosed food allergy to staple foods. Clin Transl Allergy. 2013;3:21.

9. Knibb RC, Ibrahim NF, Stiefel G, Petley R, Cummings AJ, King RM, Keeton D, Brown L, Erlewyn-La' = nesse $M$, Roberts $G$, Lucas JS. The psychological impact of diagnostic food challenges to confirm the resol +ion of peanut or tree nut allergy. Clin Exp Allergy. 2012;42(3):451-9.

10. Soller L, Hourihane J, DunnGalvin A. The impact of oral food challenge tests on food . Il 2 r $\&$ y healthrelated quality of life. Allergy. 2014;69(9):1255- 1257.

11. DunnGalvin A, Cullinane C, Daly DA, Flokstra-de Blok BM, Dubois AE, Hourı. ?ne O. Longitudinal validity and responsiveness of the Food Allergy Quality of Life Questionnaire - Parent r r $r m$ in children 0-12 years following positive and negative food challenges. Clin Exp Allergy. 2010;40/2): ${ }^{2}{ }^{\prime},-485$.

12. Franxman TJ, Howe L, Teich E, Greenhawt MJ. Oral food challenoe , nd food allergy quality of life in caregivers of children with food allergy. J Allergy Clin Immunc ; Pr rct. 015;3(1):50-56.

13. van der Valk JP, Gerth van Wijk R, Flokstra-de Blok BM, van der Velde JL, de Groot $H$, Wichers HJ, Dubois $A E$, de Jong NW. No difference in health-related qualit' $O^{\prime}$ life, after a food challenge with cashew nut in children participating in a clinical trial. Pediatr Aller, In $\ldots . .$. nol. 2016;27(8):812-817.

14. van der Velde JL, Flokstra-de Blok BM, de ( $\left.r^{\prime}, 0\right) \mathrm{H}$, Oude-Elberink JN, Kerkhof M, Duiverman EJ, Dubois AE. Food allergy-related quality of life after doubie-blind, placebo-controlled food challenges in adults, adolescents, and children. J Allergy Clin Ir..rin...Jl. 2012;130(5):1136-1143.

15. MacLeod AK, Haynes C, Sensky T. Auributions about common bodily sensations: their associations with hypochondriasis and anxiety. Psvc1. ᄀl Med. 1998;28(1):225-228.

16. Rachman S. Health aryIC ${ }^{+v}$ disorders: a cognitive construal. Behav Res Ther. 2012;50(7-8):502-12.

17. Miles A, Wardıc ' muverse psychological outcomes in colorectal cancer screening: does health anxiety play a role? Beha、 Rf $s$ Ther. 2006;44(8):1117-27.

18. $M$. cha ר ' T, Collins JP, Moss-Morris RE, Petrie KJ. Who is not reassured following benign diagnosis of breast s.'mir toms? Psychooncology. 2005;14(3):239-46.. 
19. Flokstra-de Blok BM, van der Meulen GN, DunnGalvin A, Vlieg-Boerstra BJ, Oude Elberink JN, Duiverman EJ, Hourihane JO, Dubois AE. Development and validation of the Food Allergy Quality of Life Questionnaire Adult Form. Allergy. 2009;64(8):1209-17.

20. Goldberg D, Williams P. A user's guide to the General Health Questionnaire. NFER-Nelsur V.' 'nr'sor, 1988.

21. Marteau TM, Bekker H. The development of a six-item short-form of the stat $€$ sca. $\supset$ of the Spielberger State-Trait Anxiety Inventory (STAI). Br J Clin Psychol. 1992;31(3):301-6.

22. Watson D, Clark LA, Tellegen A. Development and validation of brief mt ' sur :s of positive and negative affect: the PANAS scales. J Pers Soc Psychol. 1988;54(6):1063-70.

23. Lucock M, Morley S. The Health Anxiety Questionnaire. Britis'، Jo rnal of Health Psychology. 1996;1(2):137-150.

24. Faul F, Erdfelder E, Lang AG, Buchner A. G*Powe 2: a i iexible statistical power analysis program for the social, behavioral, and biomedical sciences. Behav kt. Niethods. 2007;39(2):175-91.

25. Schroeder A, Kumar R, Pongracic JA, Su'iivar CL, Caruso DM, Costello J, Meyer KE, Vucic Y, Gupta R, Kim JS, Fuleihan R, Wang X. Food allergy is as suclaied with an increased risk of asthma. Clin Exp Allergy. 2009;39(2):261-70.

26. Berns SH, Halm EA, Sampson hi jicherer SH, Busse PJ, Wisnivesky JP. Food allergy as a risk factor for asthma morbidity in adultc. J sthı 1. 2007;44(5):377-81.

27. Cerecedo I, Zamora J, : רx $N_{1}$, Voordouw J, Plana N, Rokicka E, Fernandez-Rivas M, Vázquez Cortés S, Reche M, Fiandor A, Kc Nals'ı M, Antonides G, Mugford M, Frewer L, De la Hoz B. The impact of doubleblind placebo- contrr.'.eu .'ud challenge (DBPCFC) on the socioeconomic cost of food allergy in Europe. J Investig Allergol Clir i.nn ,unol. 2014;24(6):418-24.

28. Couch C. $r$. `nxman T, Greenhawt M. The economic effect and outcome of delaying oral food challenge . in Allergy Asthma Immunol. 2016;116(5):420-4. 
